\title{
BROTE EPIDEMICO DE TINEA CAPITIS POR TRICHOPHYTON TONSURANS
}

\author{
ELIZABETH CASTAÑEDA, * NELLY ORDOÑEZ * *
}

\begin{abstract}
Se presenta un informe breve sobre un brote epidémico de Tinea Capitis ocurrido en un orfanato de Bogotá. En cuatro de los cinco casos se aisló como agente etiológico un dermatofito antropofílico: Trichophyton tonsurans. En otro caso se identificó T. mentagrophytes.
\end{abstract}

Las tiñas o lesiones causadas por dermatofitos son de distribución universal, variando solamente los agentes etiológicos predominantes en cada región (1).

Existen muchos informes en la literatura acerca de la gran incidencia de las tiñas en nuestro país (2-7). En lo que se refiere a la tinea capitis, que predomina en niños, el agente etiológico que se aisla con mayor frecuencia en Colombia es el Microsporum canis (8-10).

Describimos en este informe cinco casos de tinea capitis, que se presentaron en niños de una aldea para huérfanos en Bogotá. En cuatro de ellos pudimos aislar como agente etiológico Trichophyton tonsurans y en el otro T. mentagrophytes.

\section{MATERIAL Y METODOS}

\section{Pacientes}

Dos pacientes constituyeron los casos índice (J.P.T. y E.B.), de sexo masculino, edad de ocho años y habitantes de la casa No. 5. Presentaban lesiones descamativas y alopécicas en cuero cabelludo.

Microbióloga. M.Sc., Laboratorio de Micología Médica, Grupo de Microbiología e Inmunología. Instituto Nacional de Salud.

** Bióloga, Laboratorio de Micología Médica, Grupo de Microbiología e Inmunología. Instituto Nacional de Salud.
Después se examinaron los 101 niños, que vivían en las 15 casas que conformaban la aldea, buscando en ellos lesiones en la cabeza: cabello y cuero cabelludo; se tomaron muestras en 22, que presentaban lesiones: 11 hombres y 11 mujeres con edades entre los 2 y los 15 años (edad promedio = 10 años).

\section{Muestras}

Se tomaron con un bisturí, raspando el área afectada o directamente haciendo presión sobre la lesión, con el medio de cultivo en caja de Petri.

\section{Examen directo}

Para la observación microscópica se procesó la muestra con hidróxido de potasio $(\mathrm{KOH})$ al $10 \%$ adicionado de tinta Parker azul-negra 9:1.

\section{Cultivos}

Se realizaron en cajas de Petri sobre medio para dermatofitos (D.T.M.) (11). Las cajas se incubaron a $28^{\circ} \mathrm{C}$. durante ocho días.

Para observar la morfología macroscópica de las colonias aisladas en DTM, se efectuaron resiembras en agar glucosado de Sabouraud. 
Para observar la morfología microscópica se realizaron cultivos en lámina de las cepas aisladas, empleando como medio el agar glucosado de Sabouraud.

Se determinó la ureasa empleando el medio de Christensen adicionado de agar.

\section{RESULTADOS}

En la tabla No. 1 podemos observar la distribución de los cinco pacientes en los que se aisló un dermatofito, según sexo, edad, casa en que habitaban, examen directo y cultivo. Se anota también un caso en el que se aisló Chrysosporium sp.

TABLA NO. 1 - DISTRIBUCION DE LOS CASOS EN LOS QUE SE OBTUVO UN CULTIVO POSITIVO.

\begin{tabular}{lccccc}
\hline & \multicolumn{3}{c}{$\begin{array}{c}\text { Edad } \\
\text { (años) }\end{array}$} & \multicolumn{4}{c}{$\begin{array}{c}\text { Ex. } \\
\text { Caciente }\end{array}$} & Sexocto & Cultivo \\
\hline E.B. & M & 8 & 5 & $+^{*}$ & T. tonsurans \\
J.P.T. & M & 8 & 5 & $+^{*}$ & T. tonsurans \\
E.A. & M & 12 & 5 & NR & T. tonsurans \\
M.G. & M & 13 & 5 & NR & T. tonsurans \\
L.R. & F & 14 & 6 & NR & T. mentagrophytes \\
M.C. & F & 12 & 3 & NR & Chrysosporium sp*** \\
\hline
\end{tabular}

\footnotetext{
* Pelo un infección endothrix.

** Cepa identificada por la doctora Angela Restrepo. NR No realizado.
}

\section{DISCUSION}

Como anotamos anteriormente, el principal agente etiológico de tinea capitis en nuestro país es el M. canis, alcanzando su aislamiento cifras cercanas al $80 \%$ en los casos estudiados por algunos autores (9) y el $95 \%$ en nuestra experiencia de seis años en el laboratorio de micología médica. Por esta razón, el aislamiento del T. tonsurans como agente etiológico cobra importancia y debe ser considerado por los laboratorios de micología para su diagnóstico.
En nuestro estudio la tinea capitis tuvo características de forma epidémica, ya que se presentó en cuatro de los nueve niños que vivían en une de las casas. Considerando que el dermatofito aislado es una especie antropofílica, el estrecho contacto y el compartir algunos objetos de aseo pudieron ser la causa de la diseminación de la infección.

El aislamiento del T. mentagrophytes de una lesión con poca sintomatología, también debe tenerse en cuenta.

La correcta identificación del Chrysosporium sp, es muy importante ya que este género saprófito comparte algunas características macroscópicas con los dermatofitos y puede virar el medio específico para ellos (DTM); solo el examen microscópico nos permite establecer sus diferencias.

\section{SUMMARY}

An epidemy of tinea capitis which ocurred in a local orphanage is presented. In four out of five instances an antropophilic dermatophyte: Trichophyton tonsurans was isolated as the etiologic agent.

T. mentagrophytes, was identified in the remaining case.

\section{AGRADECIMIENTOS}

A todos los niños de la Aldea y a su director por su colaboración.

A la doctora Angela Restrepo y sus colaboradoras por la identificación del Chrysosporium sp. y la confirmación de los cultivos de Trichophyton tonsurans.

\section{BIBLIOGRAFIA}

1. Ajello L. The epidemiology of the dermatophytoses. En the epidemiology of human mycotic diseases. Al-Doory, Y. (ed.) Charles C Thom as. Springfield. 1965; pp 271.

2. Restrepo A, Quintero M, Moncada L, Calle G. Agentes causales de micosis superficiales en nuestro medio. Antioquia Med. 1970; 20:77. 
3. Lapides R. Prevalencia de micosis cutánea en una concentración militar. Aspectos etiológicos, profilácticos y terapéuticos. Acta Med. Valle 1970; 3:109.

4. Restrepo A, Correa I, Moncada L, Calle G. Infecciones micóticas superficiales de etiologia mixta. Informe sobre 80 casos. Antioquia Med. 1973; 23:173.

5. Guzmán MA. Micología Médica. Instituto Nacional de Salud. Bogotá. 1977; pp 139.

6. Ramírez M, Hoyos M, Larza A, Greer D. Tinea pedis en alumnos de sexto año de bachillerato en cuatro colegios de Cali. Acta Med. del Valle. 1978; 9:76.
7. Restrepo A. Dermatomicosis. En Fundamentos de Medicina. Enfermedades Infecciosas. Vélez H, Borrero J Restrepo J. (eds) $1980 ;$ pp 116.

8. Calle G, Restrepo A. Incidencia de la tinea capitis en Antioquia. Antioquia Med. 1965; $15: 361$.

9. Calle G, Restrepo A. Tinea capitis. Antioquia Med. 1965; 16:15.

10. Rodríguez R, Londoño F. Bacteriología de la tinea capitis supurada (Kerion) Bol. Lab. Clín. 1968; III (11): 19.

11. Rebell G, Taplin D. Dermatophytes their recognition and identification. University of Miami Press. 1970. 